\title{
PHÌNH TIỂU NHĨ TRÁI - BÁO CÁO TRƯờNG HỢP LÂM SÀNG
}

\author{
Lê Quang Thưu*, Nguyễn Thuc**, Đinh Thị Phuong Hoài**
}

\section{TÓM TẮT}

Phình tiểu nhĩ trái bẩm sinh là bệnh lý tim mạch hiếm gặp với nhiều biến chứng nghiêm trọng bao gồm tắc mạch huyết khối, rối loạn nhịp và rối loạn chức năng tim. Tuy nhiên, triệu chứng bệnh lại rất mơ hồ, chẩn đoán chủ yếu dựa vào siêu âm tim hoặc $\mathrm{CT}$ scan. Bài viết xin trình bày về một trường hợp lâm sàng phình tiểu nhĩ trái bẩm sinh có kích thước lớn với các triệu chứng lâm sàng không điển hình. Mục tiêu: bổ sung thêm tư liệu về trường hợp lâm sàng hiếm gặp - phình tiểu nhĩ trái - chẩn đoán và hướng điều trị.

Từ khóa: phình tiểu nhĩ trái.

\section{SUMMARY}

\section{LEFT ATRIAL APPENDAGE ANEURYSM - A CASE REPORT}

Left atrial appendage aneurysm is a rare cardiovascular disease with many serious complications including thrombosis, arrhythmias and cardiac dysfunction. However, the symptoms are very vague, the diagnosis mainly based on echocardiography or CT scan. The report presents a case of left atrial appendage aneurysm with clinical symptoms atypical. Objective: To supplement the literature on a rare clinical case Left atrial appendage aneurysm - Diagnosis and treatment.

Keyword: Left atrial appendage aneurysm

\section{I. ĐặT VẤN ĐỀ:}

Phình tiểu nhĩ trái (LAAA - Left atrial appendage aneurysm) là một bệnh lý tim mạch hiếm gặp đã được báo cáo lần đầu tiên năm 1960 [5]. Mặc dù nguyên nhân bẩm sinh, nhưng triệu chứng lâm sàng thường không xuất hiện cho đến những hai mươi hay ba mươi của cuộc đời. Một số trường hợp phình tiểu nhĩ trái được phát hiện tình cờ với các triệu chứng như hồi hộp, đánh trống ngực, khó thở, đau thắt ngực, hoặc tắc mạch do huyết khối [8], [11], [12]. Vì phình tiểu nhĩ trái có thể gây ra nhiều biến chứng nguy hiểm như tắc mạch, rối loạn nhịp, suy tim nên phẫu thuật cắt bỏ túi phình được khuyến cáo trong chỉ định [1]. Bài báo cáo của chúng tôi xin được trình bày một trường hợp lâm sàng: bệnh nhân nữ 31 tuổi vào viện vì tình cờ phát hiện túi phình tiểu nhĩ trái qua siêu âm tim với các triệu chứng lâm sàng không đặc hiệu, bệnh nhân được chỉ định phẫu thuật cắt bỏ phình tiểu nhĩ trái với hệ thống tim phổi nhân tạo. Trong báo cáo này, chúng tôi xin trình bày trường hợp lâm sàng hiếm gặp phình tiểu nhĩ trái bẩm sinh - chẩn đoán và hướng điều trị.

\section{BÁO CÁO CA LÂM SÀNG}

Bệnh nhân nữ 31 tuổi không có tiền sử gì đặc biệt vào viện vì tình cờ phát hiện phình tiểu nhĩ trái trên siêu âm tim, thỉnh thoảng có hồi hộp, mệt ngực, nhịp tim nhanh, đau tức nhẹ vùng ngực trái khi gắng sức. Điện tâm đồ bình thường; tuy nhiên, xquang ngực: phì đại thành thất trái (Hình 1), siêu âm tim qua thành ngực cho thấy túi phình tiểu nhĩ trái lớn : $\mathrm{d}=66 \times 54 \mathrm{~mm}$, túi phình lan xuống tận mặt bên trái của thất trái và chèn ép một phần vào thất trái, các buồng tim không giãn, các van tim mềm, có một ít dịch màng ngoài tim nhất là ở vùng thành bên nhĩ trái, không có dấu chèn ép tim.

* Khoa ngoại lồng ngục - tim mạch, Bệnh viện trung uong Huế

* Truòng ĐH Y-Dược Huế

Ngườ chịu trách nhiệm khoa họ: PGS.TS. Lê Quang Thưu

Ngày nhận bài: 01/05/2018 - Ngày Cho Phép Đăng: 20/05/2018

Phản Biện Khoa học: GS.TS. Bùi Đức Phú PGS.TS. Đặng Ngọc Hùng 


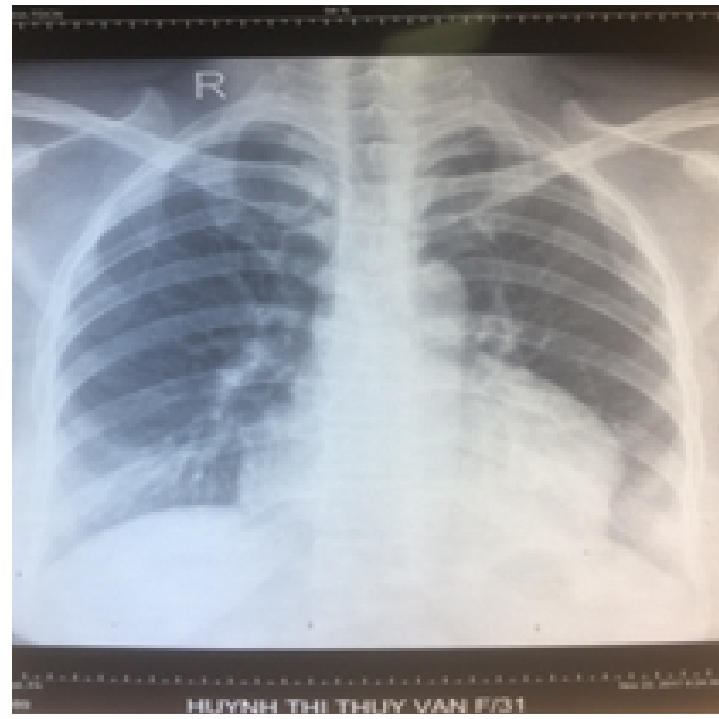

Hìn 1: Xquang ngục thẳng

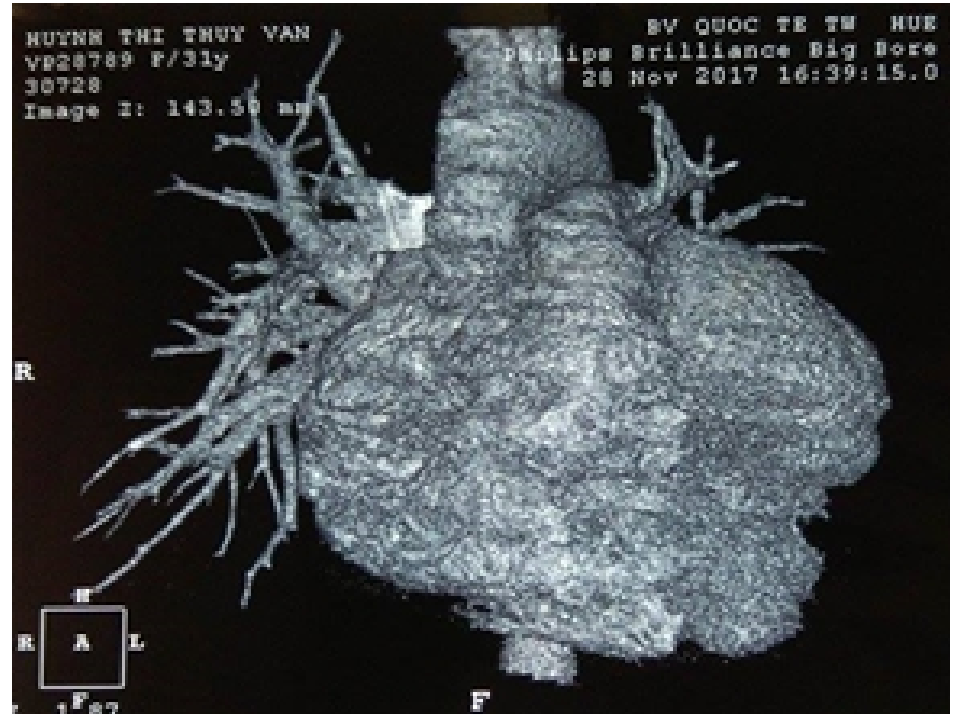

Hình 2: CT scan túi phình tiểu nhĩ trái $d=66 \times 54 \mathrm{~mm}$, gây chèn ép một phần thất trái
Dòng chảy của máu qua thông thương giữa nhĩ trái và túi phình được quan sát bằng Doppler . Phình tiểu nhĩ trái được xác định, không có huyết khối hay tín hiệu hồi âm bất thường. Chụp CT scan được thực hiện để đánh giá tình trạng của tĩnh mạch phổi và các cấu trúc xung quanh khác (Hình 2).

Bệnh nhân được chẩn đoán: phình tiểu nhĩ trái bẩm sinh và có chỉ định cắt túi phình.

\section{Lược đồ phẫu thuật ghi nhận:}

Mở ngực dọc giữa xương ức, bộc lộ túi

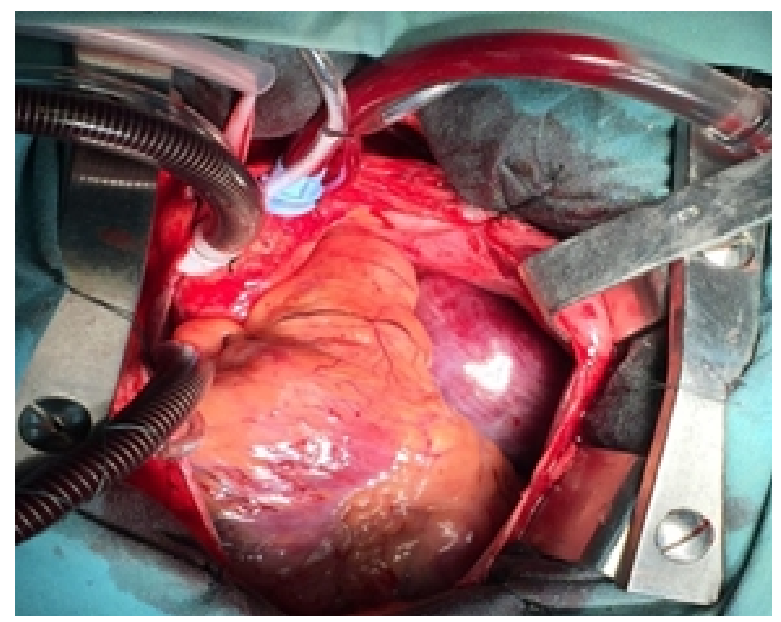

Hình 3a. phình tiểu nhĩ trái khổng lồ với màng ngoài tim nguyên vẹn. Sử dụng hệ thống tim phổi nhân tạo. Túi phình được cắt bỏ và được khâu bằng chỉ prolene 5.0. Không có huyết khối trong túi phình hoặc bất thường cấu trúc tim khác ( Hình 3a-b-c-d). Giải phẫu bệnh : phình mỏng và giãn của tiểu nhĩ trái (Hình 4). Tại thời điểm 1 tháng sau, bệnh nhân không có triệu chứng bất thường gì và siêu âm tim qua thành ngực cho thấy chỉnh sửa phình tiểu nhĩ trái tốt, tâm nhĩ không có bất thường gì.

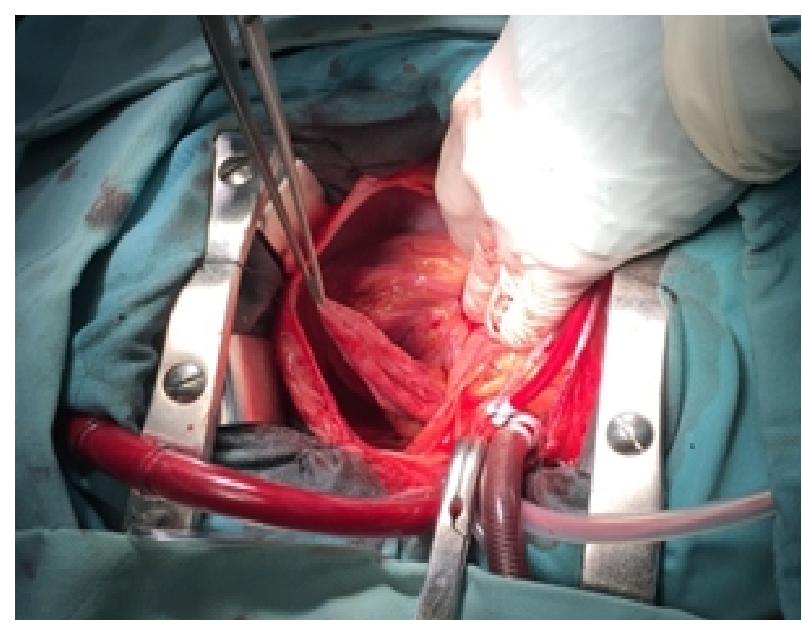

Hình 3b. 


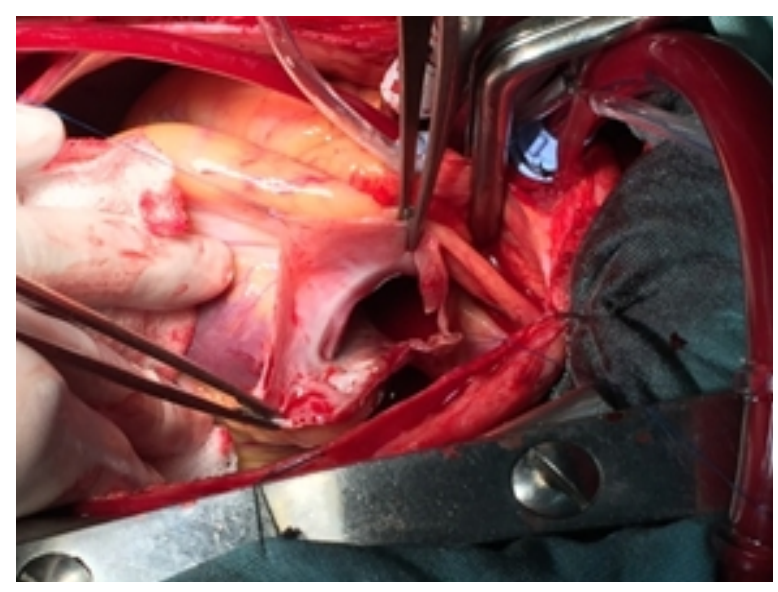

Hình 3c.

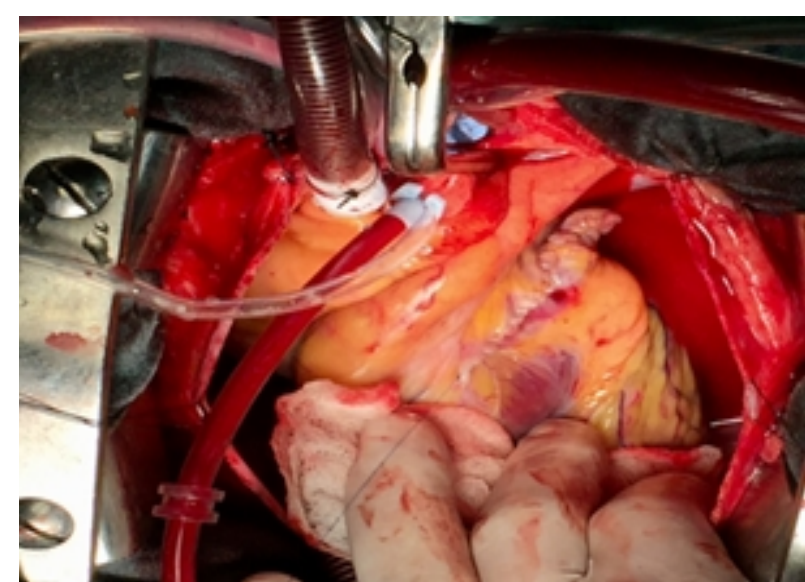

Hình 3d.

Hình 3: phẫu thuật cắt phình tiểu nhĩ trái.

\section{BÀN LUẬN}

Phình tiểu nhĩ bẩm sinh là bệnh lý tim mạch hiếm gặp và có thể bên trái hoặc bên phải, hoặc cả hai bên $[1,7]$. Đến nay, có khoảng 50 trường hợp bệnh được báo cáo trong $\mathrm{y}$ văn. Bệnh thường được phát hiện cùng với các khuyết tật khác của tim, ví dụ: hẹp ba lá [10]. Phình tiểu nhĩ trái được gọi là "khổng lồ" thường dài hơn $5 \mathrm{~cm}$. Tỷ lệ chính xác của túi phình chưa được ghi nhận; tuy nhiên, kích thước có thể tăng cùng với tuồi bệnh nhân.

Bệnh sinh có thể là do cơ tim kém co bóp do dị sản [2]. Phình tiểu nhĩ nhanh có thể gây chèn ép các cấu trúc tim khác gây ra các triệu chứng bệnh bao gồm đánh trống ngực, khó thở, loạn nhịp, và tắc mạch huyết khối thường xuất hiện cho đến những hai mươi hay ba mươi của cuộc đời [1]. Trẻ sơ sinh và trẻ nhỏ dễ bị suy tim sung huyết và suy hô hấp nặng do túi phình gây chèn ép các tĩnh mạch phổi và gây tắc nghẽn đường thở $[9,14]$.

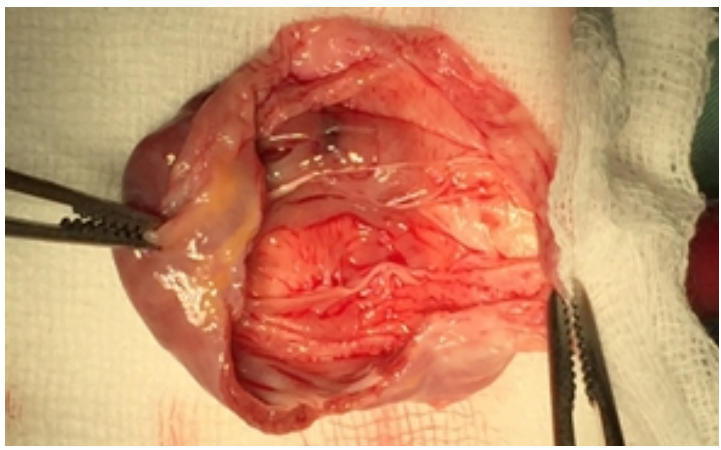

Hình 4: Phình tiểu nhĩ trái
Phình tiểu nhĩ trái mang nguy cơ biến chứng đe dọa tính mạng, bao gồm nhịp nhanh nhĩ, tắc mạch, rối loạn co bóp cơ tim và suy tim. Sớm can thiệp phẫu thuật được khuyến cáo, ngay cả trong những trường hợp không triệu chứng [3]. Tuy nhiên, một chiến lược điều trị bảo tồn đã được báo cáo trong một vài trường hợp với phình tiểu nhĩ trái khổng lồ. Plonska-Gosciniak và cộng sự báo cáo trường hợp bệnh nhân 45 tuổi, phình tiểu nhĩ trái khổng lồ $(112 \times 49 \times 80 \mathrm{~mm})$ với triệu chứng đánh trống ngực và không dung nạp với các bài tập. Bệnh nhân đã từ chối phẫu thuật và chấp nhận điều trị nội khoa. Bệnh nhân vẫn ổn định và thỉnh thoảng có rối loạn nhịp trên thất trong 20 năm theo dõi [11]. Sharma và cộng sự cũng đã báo cáo một trường hợp bệnh nhân 35 tuổi với phình tiểu nhĩ trái $(51$ x $66 \mathrm{~mm})$ và đã từ chối phẫu thuật; với triệu chứng hụt hơi, bệnh nhân được theo dõi điều trị nội khoa trong 6 tháng với chống đông bằng đường uống [12]. Những phát hiện này chỉ ra rằng điều trị nội khoa có thể được cân nhắc trong những trường hợp thiếu điều kiện cũng như trang thiết bị cho phép phẫu thuật. Tắc mạch huyết khối là một biến chứng thường gặp và nguy hiểm của phình tiểu nhĩ trái nếu không được điều trị [3]. Mặc dù không có triệu chứng thuyên tắc mạch, nhưng 
cũng không chắc chắn rằng huyết khối không hình thành nên việc chụp cộng hưởng từ não (MRI) cũng nên được xem xét, đặc biệt đối với những trường hợp không triệu chứng [16].

Điều trị nội khoa có thể là một lựa chọn cho bệnh nhân phình tiểu nhĩ trái. Mặc dù chiến lược điều trị bảo tồn này có thể làm tăng nguy cơ biến chứng, nhưng phẫu thuật cũng có nhiều thách thức. Việc sử dụng thuốc, cần phải theo dõi sát những thay đổi trong tiểu nhĩ và tâm nhĩ vì sự giãn lớn của phình tiểu nhĩ có thể gây khởi phát nhịp nhanh nhĩ [4] và có thể chèn ép cấu trúc tim lân cận như động mạch vành hoặc tâm thất như trong trường hợp của chúng tôi. Tuy nhiên, không có nghiên cứu nào xác định kích thước túi phình bao nhiêu là giảm nguy cơ biến chứng. Một nghiên cứu gần đây đã chứng minh rằng kích thước túi phình không dự đoán sự hình thành huyết khối hoặc tắc nghẽn, nhưng có thể gây nhịp nhanh nhĩ [1]. Vì vậy, theo dõi các triệu chứng lâm sàng là rất quan trọng.

Mặc dù, điều trị bảo tồn làm giảm các triệu chứng trong một số ít trường hợp, nhưng phẫu thuật nên được chỉ định đặc biệt ở trẻ sơ sinh và trẻ nhỏ do những biến chứng nghiêm trọng cũng như những bất thường hiện có khác ở tim. Mở ngực dọc giữa xương ức thường được thực hiện và phù hợp hơn các cách tiếp cận khác vì vừa để loại bỏ phình tiểu nhĩ lớn, kiểm tra có huyết khối hay không, vừa có thể chỉnh sửa đồng thời van 2 lá, trong trường hợp xuất hiện trào ngược là kết quả của sự biến dạng gây ra bởi túi phình [9]. Mặc dù cắt bỏ nội soi có thể thích hợp đối với các túi phình bẩm sinh nhỏ hơn, tuy nhiên đây là một kỹ thuật khó và cần được cân nhắc. Thủ thuật Cox-Maze II nên được thực hiện trong trường hợp tâm nhĩ lớn, giãn lớn túi phình, hoặc rung nhĩ kéo dài [13]. Sau khi phẫu thuật, hầu như không có báo cáo về tái phát các triệu chứng, ngoại trừ một bệnh nhân vẫn còn rung nhĩ, sau nhiều lần thử khử rung [8]. Trong trường hợp của chúng tôi, phẫu thuật là sự lựa chọn duy nhất để loại bỏ chèn ép vào thành thất. Thủ thuật Maze không được thực hiện bởi vì không có nhĩ lớn hoặc rung nhĩ. Siêu âm tim qua thành ngực là phù hợp và là cơ bản nhất để xác định phình tiểu nhĩ trái, có huyết khối hay các bất thường khác ở tim hay không, đồng thời cũng cung cấp những thông tin quan trọng trong chiến lược điều trị tiếp theo. Tuy nhiên, siêu âm tim qua thực quản, cung cấp chi tiết và rõ ràng hơn bao gồm dòng máu chảy qua lỗ thông và những huyết khối nhỏ và hiện cũng được khuyến cáo để phân định chính xác túi phình. Khi phình tiểu nhĩ quá lớn không thể cho hình ảnh tốt về siêu âm tim, thì CTscan và MRI là tốt hơn cả, đặc biệt là trong việc loại trừ các chẩn đoán phân biệt. Ngoài ra, vận tốc dòng chảy qua miệng chậm lại là một mối nguy hiểm với tín hiệu ứ đọng máu trong LAAA [15]. Trong những trường hợp này, tín hiệu hồi âm nên được đánh giá cẩn thận bởi vì tăng nguy cơ huyết khối tĩnh mạch thứ phát do sự ứ đọng.

Phình tiểu nhĩ trái có thể kết hợp với các bất thường tim khác, nên siêu âm tim nên đánh giá toàn bộ cấu trúc tim . Tiêu chuẩn chẩn đoán đề xuất cho bệnh nhân phình tiểu nhĩ trái bẩm sinh là: (1) nguồn gốc từ một tâm nhĩ trái bình thường , (2) thông thương rõ ràng với tâm nhĩ trái (3) nằm bên trong màng ngoài tim, và (4) gây méo mó của thành tự do của tâm thất do túi phình [6]. Phình tiểu nhĩ trái rất hiếm gặp, nhưng nó có thể đe dọa tính mạng nếu có nghẽn mạch não. Vì vậy, khi có những bệnh nhân với các triệu chứng nói trên mà không có liên quan với bệnh lý nào khác thì cần phải xem xét về một chẩn đoán phình tiểu nhĩ trái.

\section{KẾT LUẬN:}

Phình tiểu nhĩ trái là một bệnh lý hiếm gặp liên quan đến tỷ lệ tử vong về tim mạch do các biến chứng nghiêm trọng mà bệnh gây ra như rối loạn co bóp cơ tim, rối loạn nhịp tim và tắc mạch do huyết khối. Triệu chứng bệnh rất mơ hồ, chẩn 
đoán chủ yếu dựa vào siêu âm tim hoặc CT scan. Phẫu thuật cắt bỏ túi phình được khuyến cáo để ngăn ngừa những biến chứng nguy hiểm trên. Điều trị bảo tồn có thể được xem xét cho một số bệnh nhân. Đánh giá toàn diện với siêu âm tim, MRI não và các triệu chứng lâm sàng có thể sẽ hữu ích cho việc quản lý điều trị tiếp theo của LAAA.

\section{TÀI LIỆU THAM KHẢO}

[1]. Aryal MR, Hakim FA, Ghimire S, Ghimire S, Giri S, Pandit A, et al. Left atrial appendage aneurysm: a systematic review of 82 cases. Echocardiography. 2014;31(10):1312-8.

[2]. Bramlet DA, Edwards JE. Congenital aneurysm of left atrial appendage. Br Heart J. 1981;45(1):97-100.

[3]. Chowdhury UK, Seth S, Govindappa R, Jagia P, Malhotra P. Congenital left atrial appendage aneurysm: a case report and brief review of literature. Heart Lung Circ. 2009;18(6):412-6.

[4]. Cujec B, Bharadwaj B, Orchard RC, Lopez JF. Transesophageal echocardiography in the diagnosis of left atrial appendage aneurysm. J Am Soc Echocardiogr. 1990;3(5):408-11.

[5]. Diamond EG, Kittle CF, Voth DW. Extreme hypertrophy of the left atrial appendage: the case of the giant dog ear. Am J Cardiol. 1960;5:122-5.

[6]. Foale RA, Gibson TC, Guyer DE, Gillam L, King ME, Weyman AE. Congenital aneurysms of the left atrium: recognition by cross-sectional echocardiography. Circulation. 1982;66(5):1065-9.

[7]. Jonavicius K, Lipnevicius A, Sudikiene $\mathrm{R}$, Zurauskas E, Lebetkevicius V, arutis V. Surgical repair of a giant congenital right atrial aneurysm: a case report. J Cardiothorac Surg. 2015;10:72.

[8]. Kuiten WM, de Heer LM, van Aarnhem EE, Onsea K, van Herwerden LA. Giant left atrial appendage: a rare anomaly. Ann Thorac Surg. 2013; 96(4):1478-80.

[9]. Morales JM, Patel SG, Jackson JH, Duff JA, Simpson JW. Left atrial aneurysm. Ann Thorac Surg. 2001;71(2):719-22.

[10]. Pawar R, Patel S, Vs K, Pv S, Rao S. Giant left atrial appendage aneurysm in association with tricuspid atresia. Eur Heart J Cardiovasc Imaging. 2016;17(3):352.

[11]. Plonska-Gosciniak E, Larysz B, Jurczyk K, Kasprzak JD. Five-chambered heart: a20-year story of left atrial appendage aneurysm. Eur Heart J. 2009;30(8):1014.

[12]. Sharma J, Kapoor A. The fifth cardiac chamber: case of a huge left atrial appendage aneurysm. Indian J Med Res. 2015;142(6):770-1.

[13]. Shih YJ, Lin YC, Tsai YT, Lin CY, Lee CY, Yang HY, et al. Left atrial appendage aneurysm with paroxysmal atrial fibrillation. Heart Surg Forum. 2012;15(1):E1-3.

[14]. Stone KS, Brown JW, Canal D, Caldwell R, Hurwitz R, King H. Congenital aneurysm of the left atrial wall in infancy. Ann Thorac Surg. 1990;49(3):476-8.

[15]. Ulucam M, Muderrisoglu H, Sezgin A. Giant left atrial appendage aneurysm: the third ventricle! Int J Cardiovasc Imaging. 2005;21(23):225-30.

[16]. Yan Chen, Yun Mou, Li-Jun Jiang and Shen-Jiang $\mathrm{Hu}$, Congenital giant left atrial appendage aneurysm: a case report. Journal of Cardiothoracic Surgery (2017) 12:15 , DOI 10.1186/s13019-017-0576-6. 